\title{
Stereoselective Synthesis of Tetrahydroindolizines via Catalytic Formation of Pyridinium Ylides from Diazo Compounds
}

\author{
Jonathan Day, ${ }^{[\mathrm{a}]}$ Ben McKeever-Abbas,${ }^{[\mathrm{b}]}$ and James Dowden ${ }^{*[\mathrm{a}]}$
[a] Dr Jonathan Day, Dr J. Dowden
School of Chemistry, University of Nottingham
University Park, Nottingham NG7 2RD (UK)
E-mail: james.dowden@nottingham.ac.uk \\ [b] Dr Ben McKeever-Abbas \\ Pharmaceutical Development, AstraZeneca \\ Silk Road Business Park, Macclesfield, UK
}

Abstract: Commercially available iron (III) and copper (I) complexes catalyze new multicomponent cycloadditions between diazo compounds, pyridines and electrophilic alkenes to give alkaloid-inspired tetrahydroindolizidines in high yields and diastereoselectivities. Hitherto, catalytic formation of versatile pyridinium ylides from metal carbenes has been poorly developed; the broad utility demonstrated herein sets the stage for invention of further multicomponent reactions in future.

Indolizidines are found in many bio-active alkaloids, ${ }^{[1]}$ whereas their unsaturated indolizine counterparts have valuable photochemical properties. ${ }^{[2,3]}$ Both structures are valued for their therapeutic potential. ${ }^{[4-6]}$ Spirooxindoles have also been identified as privileged scaffolds for drug discovery. ${ }^{[7]}$ Efficient and versatile routes toward these structural motifs are highly desirable therefore.

Convergent synthesis of tetrahydroindolizidines can be achieved by 1,3-dipolar cycloaddition of pyridinium ylides with electrophilic alkenes. The resulting products may then be converted into indolizines by oxidation, ${ }^{[8-10]}$ or into indolizidines by reduction or other type of functionalization (Scheme 1). ${ }^{[11,12]}$

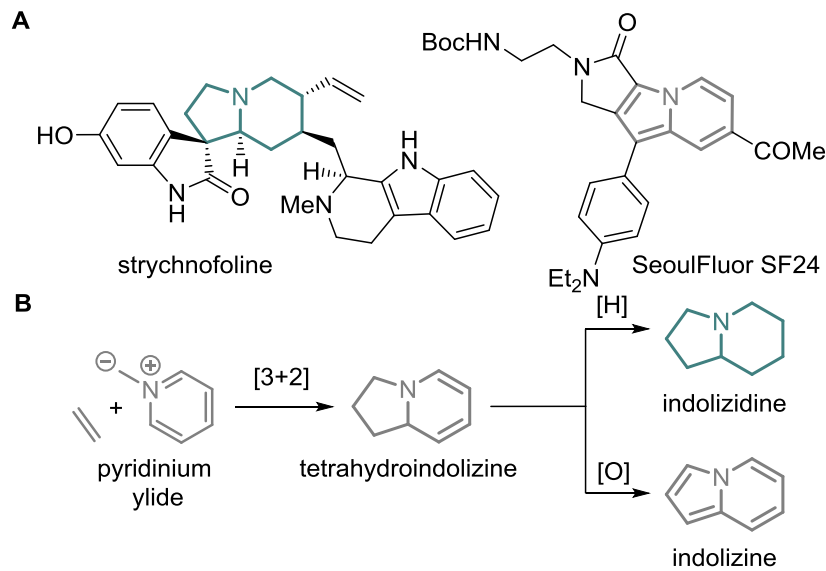

Scheme 1. A: Examples of an indolizidine-containing alkaloid and an indolizine dye; B: a cycloaddition route to tetrahydroindolizidines.

Typically, pyridinium ylides are formed by deprotonation of the corresponding salts but this protocol produces stoichiometric conjugate acid waste and usually requires a separate 
alkylation step to prepare the pyridinium salts. Such drawbacks significantly restrict the utility of otherwise versatile synthetic intermediates.

In principle, catalytic reactions that directly transform pyridines into their corresponding ylides under aprotic conditions, and in the presence of electrophilic alkenes, open up the prospect of more powerful multicomponent reactions to prepare tetrahydroindolizidines. The addition of Lewis bases to metal carbenes to form ylides has been widely developed for synthesis, ${ }^{[13-20]}$ but there are few reports of catalysed reactions of pyridines with diazo compounds. ${ }^{[21,22]}$ The generation of pyridinium ylides in this way has received surprisingly little attention; in fact, we could find only a single example of this type of catalysed three component reaction to form an indolizine. ${ }^{23]}$

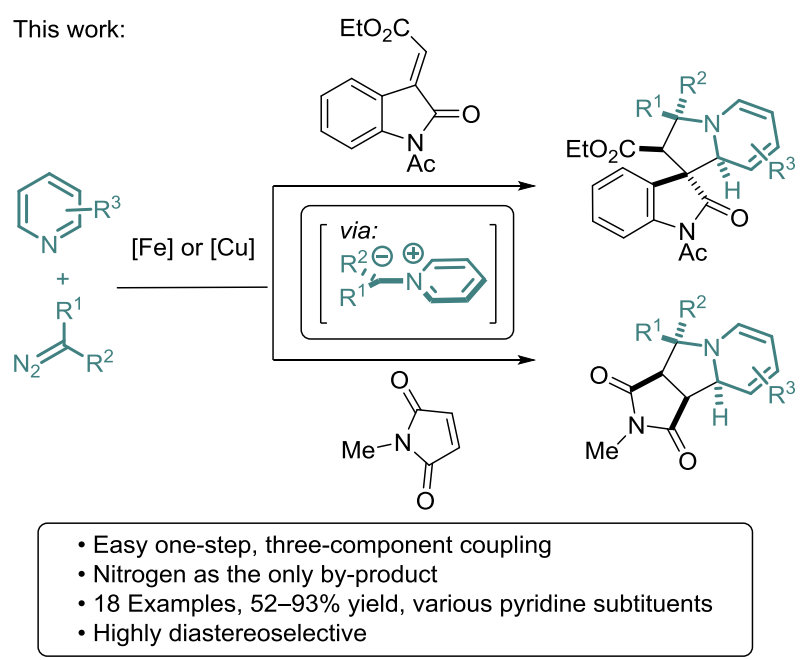

Scheme 2. Synthesis of pyridinium ylides and use for indolizidine synthesis.

In principle, catalytic reactions that directly transform pyridines into their corresponding ylides under aprotic conditions, and in the presence of electrophilic alkenes, open up the prospect of more powerful multicomponent reactions to prepare tetrahydroindolizidines. The addition of Lewis bases to metal carbenes to form ylides has been widely developed for synthesis, ${ }^{[13-20]}$ but there are few reports of catalysed reactions of pyridines with diazo compounds. ${ }^{[21,22]}$ The generation of pyridinium ylides in this way has received surprisingly little attention; in fact, we could find only a single example of this type of catalysed three component reaction to form an indolizine. ${ }^{23]}$

Herein, we describe a new, multicomponent reaction that produces highly functionalized tetrahydroindolizidines in good yields with generally excellent diastereoselectivities (Scheme 2). These reactions involve catalytic generation of pyridinium ylides via metallocarbenes and in situ cycloaddition with electrophilic alkenes. This highly efficient route generates nitrogen as the only by-product. The choice of catalyst is critical to the reaction outcome (Scheme 3), the most effective being commercially available complexes derived from the abundant base metals iron (III) or copper (I). 


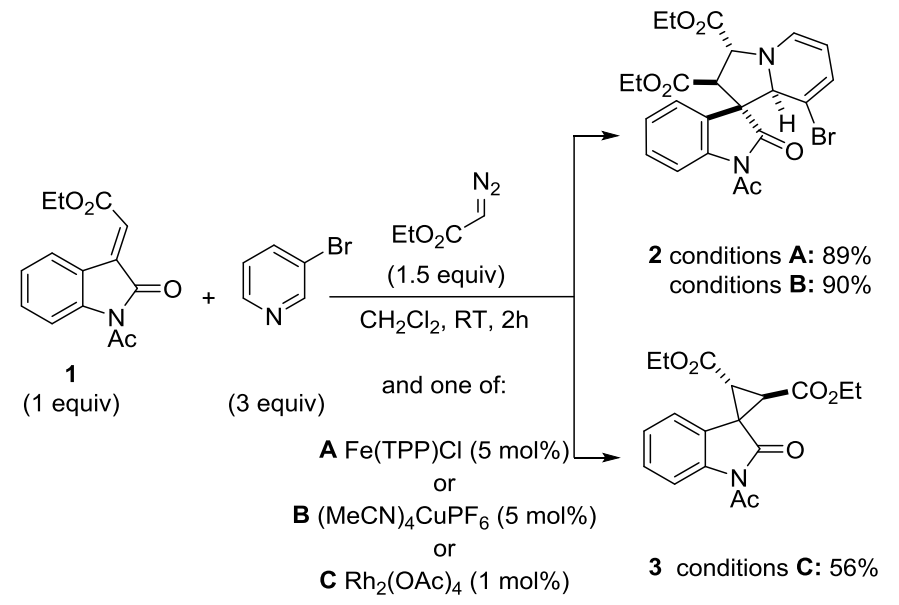

Scheme 3. Rhodium-, copper- or iron-catalyzed reaction of 3-bromopyridine, ethyl diazoacetate and ethyl ('E)-2-(1-acetyl-2-oxoindolin-3-ylidene)acetate (1).

We first examined reaction between 3-alkenyloxindole 1, 3-bromopyridine and ethyl diazoacetate and various catalysts (Scheme 3). Satisfyingly, tetrahydroindolizidine 2 was obtained as the sole product in good yield (89-90\%) as a single diastereoisomer when either 5 mol\% of $\mathrm{Fe}(\mathrm{TPP}) \mathrm{Cl}$ or $(\mathrm{MeCN})_{4} \mathrm{CuPF}_{6}$ were used. The NMR data of 2 suggested that the sense of diastereoselectivity was the same as related products prepared by conventional base-promoted ylide formation. ${ }^{[24]}$

Cyclopropane 3 was obtained as the only product when $\mathrm{Rh}_{2}(\mathrm{OAc})_{4}(1 \mathrm{~mol} \%)$ was used as the catalyst, however. A catalyst loading of $1 \mathrm{~mol} \%$ of $\mathrm{Fe}(\mathrm{TPP}) \mathrm{Cl}$ in toluene led to similar yields of 2 (89\%), so these conditions were used.

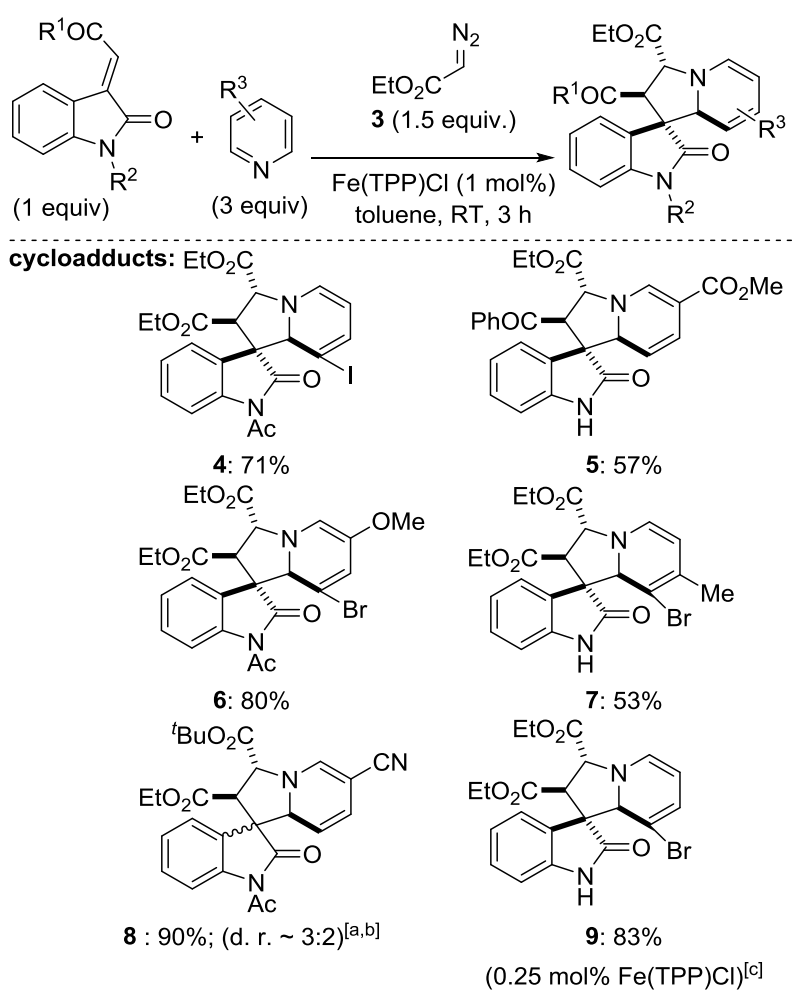

Scheme 4. Synthesis of tetrahydroindolizidines from pyridines. ${ }^{[a]}$ Synthesized from tert-butyl diazoacetate. ${ }^{[b]}$ Ratio based on isolated yield of each diastereoisomer. $\left.{ }^{c}\right]$ Using $0.25 \mathrm{~mol} \%$ $\mathrm{Fe}(\mathrm{TPP}) \mathrm{Cl}$ on a $1.3 \mathrm{mmol}$ scale. 
Next, reactions were performed with a variety of pyridines (Scheme 4). Good yields were generally obtained with electron-withdrawing groups at the 3-position of the pyridine. For example, 3-iodopyridine reacted with oxindole $\mathbf{1}$ analogously to 3-bromopyridine to produce tetrahydroindolizine $\mathbf{4}$ in a similarly good yield (71\%). Reaction of ethyl diazoacetate, methyl nicotinate and 3-phenacylideneoxindole, gave cycloadduct 5 albeit in a relatively lower yield (57\%). Overall, yields were not significantly affected if the 3alkenyloxindole nitrogen atom was unprotected. Bromopyridines featuring another substituent were also effective reagents. For example, cycloadducts 6 and 7 were prepared in $80 \%$ and $53 \%$ yield from 3-bromo-5-methoxypyridine and 3-bromo-4-methylpyridine, respectively. The reaction of 3-cyanopyridine with tert-butyl diazoacetate and oxindole 1 gave a mixture of two diastereoisomers 8 in a $90 \%$ combined yield and diastereomeric ratio of about 3:2, the minor component corresponding to inversion of the spirocentre. ${ }^{[24]}$ Subsequently, a reaction performed on $1.3 \mathrm{mmol}$ scale with $0.25 \mathrm{~mol} \%$ of $\mathrm{Fe}(\mathrm{TPP}) \mathrm{Cl}$ gave cycloadduct 9 in good yield (83\%) but lower catalysts loadings $(0.1 \mathrm{~mol} \%)$ gave inferior yields (25\%).

Reaction of 4-trifluoromethylpyridine with various oxindoles (Scheme 5) was next evaluated. Cycloadducts 10 and 11 were obtained in excellent yields from 1 or the deacetylated equivalent in $93 \%$ or $92 \%$ respectively (d.r. 4:1). ${ }^{[25]}$ (E)-3Phenacylideneoxindole was also effective leading to tetrahydroindolizidine $\mathbf{1 2}$ in $73 \%$ yield as a single diastereoisomer. Notably, (Z)-3-phenacylideneoxindole gave cycloadduct 12 with the same sense of diastereoselectivity and comparable yield. Substrates containing electronwithdrawing $\left(\mathrm{R}^{1}=\mathrm{NO}_{2}\right)$ or electron-donating groups $\left(\mathrm{R}^{1}=\mathrm{OMe}\right)$ at the 5-position of the oxindole were tolerated, and reacted to give products 13 (85\% yield) and 14 (92\% yield), respectively. Similarly, cycloadduct 15 was obtained as a single diastereoisomer in $71 \%$ yield.

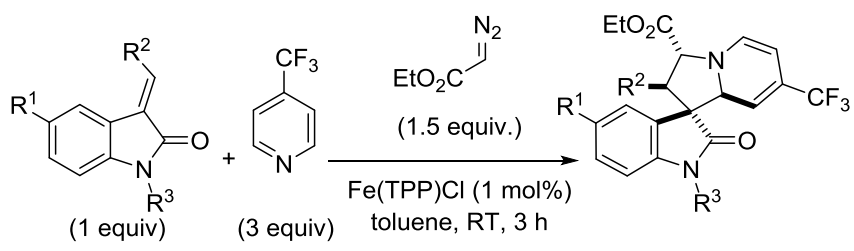

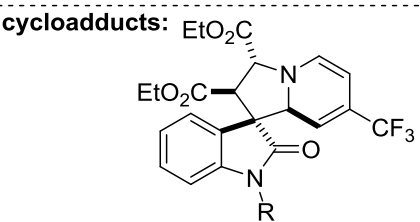

$10(\mathrm{R}=\mathrm{Ac}): 93 \%(\text { d.r. } 4: 1)^{[\mathrm{a}]}$

$11(\mathrm{R}=\mathrm{H}): 92 \%$ (d.r. $4: 1)^{[\mathrm{a}]}$

$\mathrm{EtO}_{2} \mathrm{C}$<smiles></smiles>

13: $85 \%$ (d.r. $9: 2)^{[a]}$

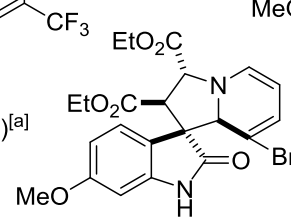<smiles>CCOC[C@H]1[C@H](COP)[C@@]2(C(=O)Nc3ccccc32)[C@@H]2C=C(C(F)(F)F)C=CN21</smiles>

12: $73 \%{ }^{[\mathrm{b}]}$<smiles>CCOC[C@H]1C(C)[C@@]2(C(=O)Nc3ccc(OC)cc32)[C@@H]2C=C(C(F)(F)F)C=CN21</smiles>

14: $92 \%(\text { d.r. } 6: 1)^{[a]}$

15: $71 \%$

Scheme 5. Synthesis of tetrahydroindolizidines from various 3-alkenyloxindoles ${ }^{\text {[a] }}$ Diastereomeric ratio determined by NMR analysis. ${ }^{\text {b }}$. Synthesized from either $(E)-3$ phenacylideneoxindole or (Z)-3-phenacylideneoxindole.

Reaction with different electrophilic alkenes were equally productive, thus cycloadducts 16-18 were obtained in good yields as single diastereoisomers from reactions of $\mathrm{N}$ methylmaleimide with 3-bromopyridine (97\%), 4-trifluoromethylpyridine (94\%), and 3-bromo5-methoxypyridine (84\%), respectively (Scheme 6). 


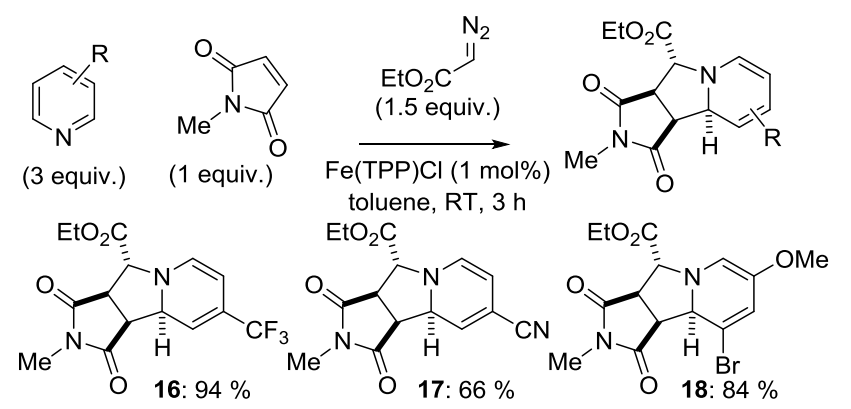

Scheme 6. Synthesis of tetrahydroindolizidines from $N$-methylmaleimide.

Alternative diazo precursors were investigated with a view to broadening the range of alpha-substituted pyridinium ylides. Diazophenylacetic acid-derived pyridine 19 did not undergo cyclization with oxindole 1 using catalytic $\mathrm{Fe}(\mathrm{TPP}) \mathrm{Cl}$ in toluene (Scheme 7). More effective reaction was obtained using 5 mol\% of $(\mathrm{MeCN})_{4} \mathrm{CuPF}_{6}$ pre-catalyst in $\mathrm{CH}_{2} \mathrm{Cl}_{2}$, which previously returned high yields of product 2 (Scheme 3), leading to a $57 \%$ yield of cycloadduct 20. Cycloadduct 21 was obtained in 70\% yield following reaction with $\mathrm{N}$ methylmaleimide. Similar results were obtained for intermolecular ylide generation from ethyl diazophenylacetate; (MeCN) ${ }_{4} \mathrm{CuPF}_{6}$ gave a $59 \%$ yield of cycloadduct 22 , but no cycloadduct was produced using Fe(TPP)Cl. All cycloadducts 20-22 were obtained as single diastereoisomers. Single crystal X-ray diffraction of $\mathbf{2 2}$ revealed both ester groups to be on the same face, unlike the preceding examples. ${ }^{[26}$

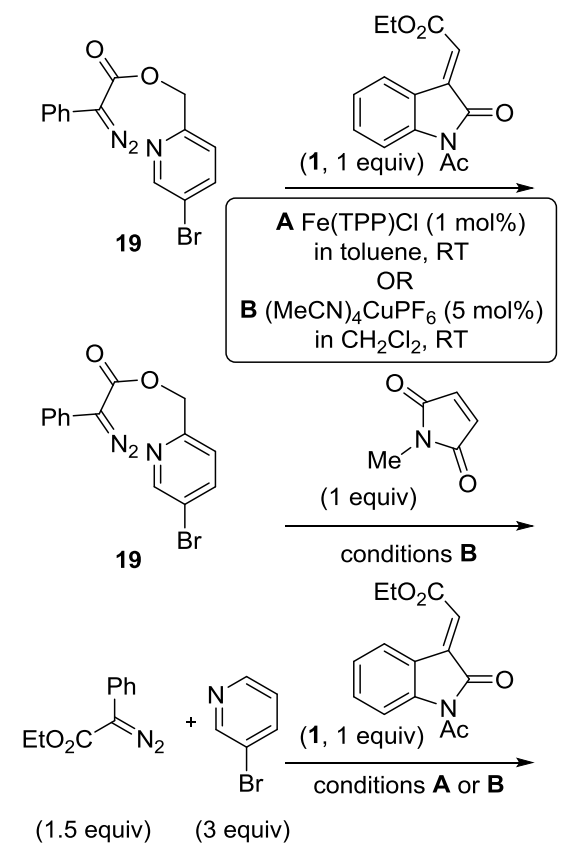

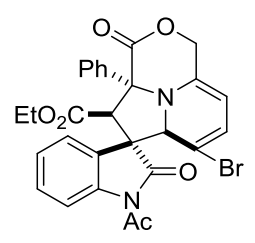

20: conditions $\mathbf{A}=0 \%$; conditions $\mathbf{B}=57 \%$

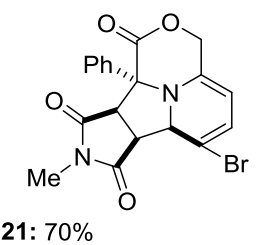

21: $70 \%$<smiles>CCOC(=O)C1(c2ccccc2)c2ccccc2[C@@]2(C(=O)N(C)c3ccccc32)[C@H]1C</smiles>

22: conditions $\mathbf{A}=0 \%$; conditions $\mathbf{B}=59 \%$

Scheme 7. Synthesis of tetrahydroindolizidines from $\square$-branched diazo compounds.

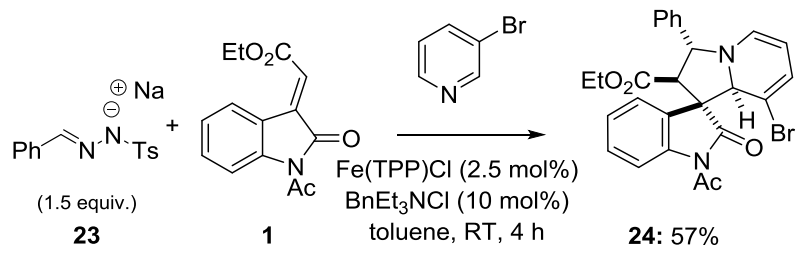


Scheme 8. Synthesis of tetrahydroindolizidines from diazo compound generated in situ

In situ generation of diazo compounds from tosylhydrazone salts, ${ }^{[27]}$ was briefly investigated and promising yields of cycloadduct $\mathbf{2 4}$ were obtained from reaction of benzylidene hydrazone salt 23 (57\%, Scheme 8). This benign reactivity and broad range of possible tosylhydrazones encourages detailed future investigation.

Next, control experiments were conducted to rule out a non-catalyzed reaction pathway (Scheme 9). Reaction of tert-butyl diazoacetate with oxindole 1 in toluene at ambient temperature only gave spiropyrazole 25 cycloadduct $(66 \%) .{ }^{[26]}$ Similar pyrazoles have been reported to contract to cyclopropanes upon heating ${ }^{[28-30]}$ but this possibility was ruled out when starting materials were returned upon subjecting spiropyrazole 25 to 3-bromopyridine and $\mathrm{Fe}(\mathrm{TPP}) \mathrm{Cl}(10 \mathrm{~mol} \%)$ in toluene at room temperature. Cyclopropanes could also

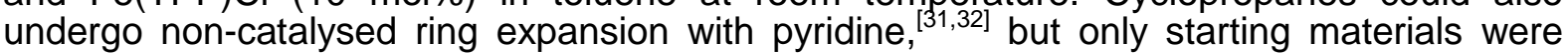
obtained from reaction of cyclopropane $\mathbf{3}$ using the latter reaction conditions.

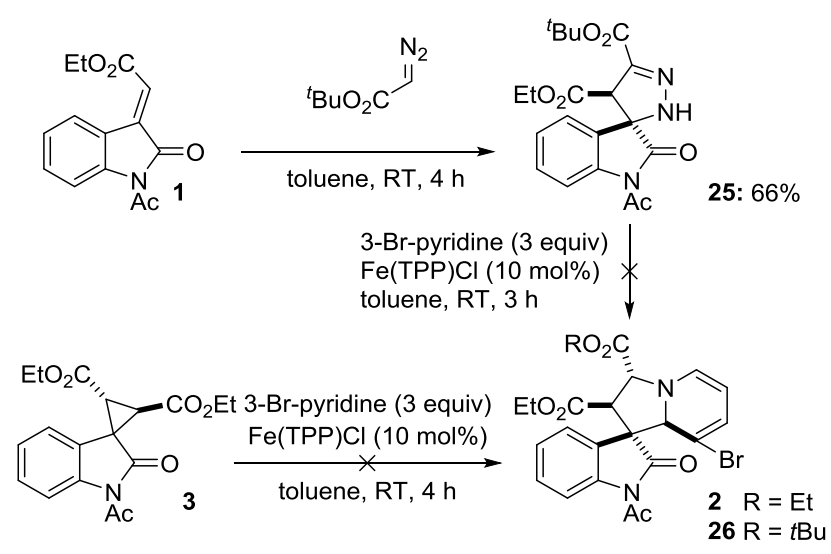

Scheme 9. Control experiments.

These control experiments reinforce the idea that nucleophilic pyridines add to a metal carbene $\mathbf{A}$ or diazonium ylide $\mathbf{B}$ leading to pyridinium ylide $\mathbf{C}$ (Scheme 10). That cycloadduct 12 is obtained regardless of starting oxindole configuration suggests a stepwise mechanism involving 1,4-addition of the pyridinium ylide to the alkenyloxindole through transition state $\mathbf{D}$, followed by cyclization of a zwitterionic intermediate through transition state $\mathbf{E}$. The observed anti relative configuration of the ester groups at $\mathrm{C}-3^{\prime}$ and $\mathrm{C}-\mathrm{2}^{\prime}$ in the product 4 can be explained by minimized dipole-dipole repulsions between the respective carbonyl groups in transition state $\mathbf{D}^{[33]}$ The relative configuration of the spirocyclic centre $(\mathrm{C}-3)$ and ring junction (C-8a') in the cycloadduct 4 can be explained by an attractive interaction between electron deficient pyridinium and electron rich oxindole during ring-closing step $\mathbf{E}$. 


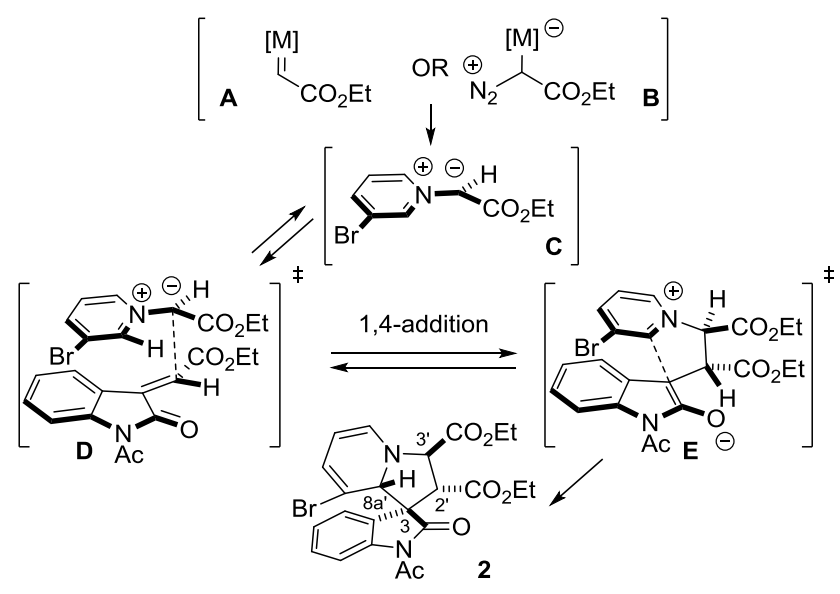

Scheme 10. Proposed mechanism to rationalize observed stereoselective formation of tetrahydroindolizidines through reactions involving catalytic production of pyridinium ylides from diazo compounds.

In conclusion, we have developed iron- or copper-catalyzed stereoselective reactions involving pyridines, diazo compounds and electrophilic alkenes that give efficient synthesis of alkaloid-like tetrahydroindolizidines that are a privileged scaffold for drug discovery. ${ }^{[7]}$ An important observation is that pyridinium ylide production from metal carbenes is general and compatible with multicomponent reactions since this aprotic route to pyridinium ylides has received little attention to date. We envisage that these findings will stimulate development of a much wider repertoire of reactions by variation of electrophile, and chiral catalysts for enantioselective reactions.

\section{Acknowledgements}

We thank the EPSRC (EP/J021008/1), AstraZeneca and the University of Nottingham for support.

Keywords: cycloaddition • carbenes• homogenous catalysis • diazo compounds $\bullet$ pyridinium ylides

[1] J. P. Michael, Nat. Prod. Rep. 2008, 25, 139-165.

[2] E. J. Choi, E. Kim, Y. Lee, A. Jo, S. B. Park, Angew. Chem. Int. Ed. 2014, 53, 13461350; Angew. Chem. 2014, 126, 1370-1374.

[3] M. K. Bayazit, K. S. Coleman, J. Am. Chem. Soc. 2009, 131, 10670-10676.

4] P. Chen, A. Chaikuad, P. Bamborough, M. Bantscheff, C. Bountra, C.-w. Chung, O. Fedorov, P. Grandi, D. Jung, R. Lesniak, M. Lindon, S. Müller, M. Philpott, R. Prinjha, C. Rogers, C. Selenski, C. Tallant, T. Werner, T. M. Willson, S. Knapp, D. H. Drewry, J. Med. Chem. 2015.

[5] W.-G. Lee, R. Gallardo-Macias, K. M. Frey, K. A. Spasov, M. Bollini, K. S. Anderson, W. L. Jørgensen, J. Am. Chem. Soc. 2013, 135, 16705-16713.

[6] G. Lemercier, A. Fernandez-Montalvan, J. P. Shaw, D. Kugelstadt, J. Bomke, M. Domostoj, M. K. Schwarz, A. Scheer, B. Kappes, D. Leroy, Biochemistry 2009, 48, 6379-6389.

[7] C. V. Galliford, K. A. Scheidt, Angew. Chem. Int. Ed. 2007, 46, 8748-8758; Angew. Chem. 2007, 119, 8902-8912.

[8] B. X. Wang, X. C. Zhang, J. Li, X. Jiang, Y. F. Hu, H. W. Hu, J, Chem. Soc. Perkin Trans. 11999, 1571-1575.

[9] J. Brioche, C. Meyer, J. Cossy, Org. Lett. 2015, 17, 2800-2803.

101 D. S. Allgaeuer, P. Mayer, H. Mayr, J. Am. Chem. Soc. 2013, 135, 15216-15224.

11 B. V. M. Teodoro, J. T. M. Correia, F. Coelho, J. Org. Chem. 2015, 80, 2529-2538.

[12] N. Ortega, D.-T. D. Tang, S. Urban, D. Zhao, F. Glorius, Angew. Chem. Int. Ed. 2013, 52, 9500-9503; Angew. Chem. 2013, 125, 9678-9681.

[13] D. M. Hodgson, F. Pierard, P. A. Stupple, Chem. Soc. Rev. 2001, 30, 50-61. 
[14] V. K. Aggarwal, J. R. Fulton, C. G. Sheldon, J. de Vicente, J. Am. Chem. Soc. 2003, 125, 6034-6035.

[15] V. K. Aggarwal, C. L. Winn, Acc. Chem. Res. 2004, 37, 611-620.

16 S. F. Zhu, Q. L. Zhou, Acc. Chem. Res. 2012, 45, 1365-1377.

17. X. Zhao, Y. Zhang, J. B. Wang, Chem. Commun. 2012, 48, 10162-10173.

18. D. Gillingham, N. Fei, Chem. Soc. Rev. 2013, 42, 4918-4931.

$19]$ X. Guo, W. H. Hu, Acc. Chem. Res. 2013, 46, 2427-2440.

20 S. M. Nicolle, C. J. Moody, Chem. Eur. J. 2014, 20, 4420-4425.

[21] J. Barluenga, G. Lonzi, L. Riesgo, L. A. López, M. Tomás, J. Am. Chem. Soc. 2010, 132, 13200-13202.

[22] X. Xu, P. Y. Zayalij, M. P. Doyle, J. Am. Chem. Soc. 2013, 135, 12439-12447.

23 A. Padwa, D. J. Austin, L. Precedo, L. Zhi, J. Org. Chem. 1993, 58, 1144-1150.

[24] J. Day, M. Uroos, R. A. Castledine, W. Lewis, B. McKeever-Abbas, J. Dowden, Org. Biomol. Chem. 2013, 11, 6502-6509.

[25] Diastereomeric ratio measured by relative integration of ${ }^{1} \mathrm{H}$ NMR. The relative stereochemistry of the minor diastereoisomer was assumed to be analogous to the spiroinversion observed for nitrile $\mathbf{8}$.

[26] CCDC 1436938 (22) and 1436939 (25) contain the supplementary crystallographic data for this paper. These data are provided free of charge by The Cambridge Crystallographic Data Centre.

[27] J. R. Fulton, V. K. Aggarwal, J. de Vicente, Eur. J. Org. Chem. 2005, 1479-1492.

28. A. Franke, Justus Liebigs Ann. Chem. 1978, 1978, 717-725.

29] R. A. Maurya, C. N. Reddy, G. S. Mani, J. S. Kapure, P. R. Adiyala, J. B. Nanubolu, K. K. Singarapu, A. Kamal, Tetrahedron 2014, 70, 4709-4717.

[30] T.-R. Li, S.-W. Duan, W. Ding, Y.-Y. Liu, J.-R. Chen, L.-Q. Lu, W.-J. Xiao, J. Org. Chem. 2014, 79, 2296-2302.

[31] A. Lerchner, E. M. Carreira, J. Am. Chem. Soc. 2002, 124, 14826-14827.

32. J. Liu, L. Zhou, W. Ye, C. Wang, Chem. Commun. 2014, 50, 9068-9071.

[33] Presumably the phenyl group dictates the selectivity observed for cycloadduct 22. 